ORIGINAL RESEARCH PAPER

\title{
FREEZE-DRYING MICROENCAPSULATION OF TURMERIC (CURCUMA LONGA L.) USING AN AMORPHOUS MATRIX OF MALTODEXTRIN, MODIFIED CASSAVA FLOUR AND SKIM MILK
}

\author{
HARVEY FEBRIANTA $^{1 *}$, VITUS DWI YUNIANTO ${ }^{1}$, NURWANTORO NURWANTORO ${ }^{1}$, \\ VALENTINUS PRIYO BINTORO ${ }^{1}$ \\ ${ }^{1}$ Faculty of Animal and Agricultural Sciences, Diponegoro University, Semarang, Central Java, Indonesia \\ *Corresponding author: harvey606254@gmail.com
}

Received on 15 April 2020

Revised on 21 September 2020

\begin{abstract}
This study aimed to evaluate the effect of freeze-drying microencapsulation of turmeric (Curcuma longa L.) assessing the influence of wall materials on microstructure characteristics, physicochemical composition, phytochemical, antioxidant properties, and in vitro release studies of turmeric microcapsules. The following four different samples were created: turmeric control (T0), turmeric in an amorphous matrix of maltodextrin (T1), turmeric in an amorphous matrix of modified cassava flour (T2), and turmeric in an amorphous matrix of skim milk (T3). The optimal treatment process was freeze-drying microencapsulation of turmeric polyphenols in an amorphous matrix of maltodextrin (T1), since it enabled high bioactive compounds with low values of moisture, water activity (aw), and curcumin release. Maltodextrin as a coating material in turmeric affected the increased level of yield, encapsulation efficiency, and microcapsule solubility. For instance, it showed a positive effect on the value of the total phenolic content, total flavonoid content, total tannin content, ascorbic acid, and consequently led to higher antioxidant activity. Turmeric (Curcuma longa L.) with the addition of maltodextrin can be used as a natural antioxidant compound and natural colorant for food products.
\end{abstract}

Keywords: turmeric, antioxidant, microencapsulation, freeze-drying, maltodextrin, modified cassava flour, physicochemical, phytochemical, skim milk, in vitro

\section{Introduction}

Turmeric (Curcuma longa L.) belongs to the ginger family, being widely grown in the south and southwest Asia (Gupta et al., 2013). Curcumin is the bioactive chemical constituent in turmeric. Curcumin contains lipophilic polyphenol substance which generally has an orange-yellow color (Kocaadam and Sanlier,

https://doi.org/10.35219/foodtechnology.2020.2.02 
2015). The study of Miean and Mohamed (2001) reported that curcuminoids have a high bioactive activity such as antioxidant compounds.

The high value of moisture associated with nutrient loss present in turmeric causes a decrease in its shelf life. The application of technology capable of protecting bioactive compounds in turmeric at an affordable cost is a basic point for wider use in the food industry. The application of turmeric extract for encapsulation can effectively protect bioactive compounds. Microencapsulation is a method used to protect active components in turmeric, by converting them into useful forms and thus being able to provide a barrier between sensitive bioactive compounds and the external environment (Jeyakumari et al., 2016). The study from Nedovic et al. (2011) reported that microencapsulation is a coating method that can be used to cover bioactive compounds, increase bioavailability, and stabilize the sensitive compound by providing an amorphous barrier matrix around the product.

The microencapsulation process has several advantages, i.e. it can protect the sensitive food components, extend the shelf life, reduce nutrient loss, increase the usability in foodstuffs, protect the flavor, and change the food component from the liquid phase into an easier to handle solid phase (Palamutoglu and Sarıçoban, 2019). The choice of the encapsulant substance is a fundamental factor for the stability of the emulsion before the freeze-drying process, and the amorphous matrix can increase the physical stability and shelf life of the product (Calvo et al., 2011). The microencapsulation material can be developed from a variety of natural ingredients, including maltodextrin, modified cassava flour, and skim milk.

One of the modified carbohydrates aiding in microencapsulation stability is maltodextrin. The main function of maltodextrin is to protect against unwanted physical and chemical changes, such as oxidation and decomposition of the encapsulated material (Galmarini et al., 2009). Maltodextrin has good encapsulant properties because of its ability to form emulsions and low viscosity. The modification of cassava flour (Mocaf) is derived from the fermentation treatment of cassava. Lactic acid bacteria (BAL) have an important role in the fermentation process, where their activity can produce pectinolytic and cellulolytic enzymes which can partially solubilize cassava cell walls, as well as hydrolyze starch to organic acids (Putri et al., 2018). The modification of cassava flour triggers specific characteristics, i.e. it can be used as food ingredients on a very broad scale (Dudu et al., 2019). Modified cassava flour can be used as a microencapsulation material because it improves stability as a matrix compound. Another microencapsulation compound is skim milk. Fu and Chen (2011) stated that skim milk has potential effects on cell viability during dehydration.

Freeze-drying is a dehydration process in low temperatures. The mechanism of freeze-drying is freezing the product, lowering the pressure, then removing the water from materials by sublimation. Vesterlund et al. (2012) stated that the freezedrying process improves the quality and storage periods by inhibiting bacterial growth. Miyamoto-Shinohara et al. (2000) also stated that freeze-drying improves the characteristics of the product, such as composition stability, protection in terms of bioactive compound degradation, nutrients protection, minimizes the 
degradation because of heat treatment, and reduces the amount of moisture by sublimation.

The freeze-drying microencapsulation of turmeric (Curcuma longa L.) which contains maltodextrin, modified cassava flour, and skim milk as an amorphous matrix will simultaneously extend shelf life and increase usability in foodstuffs. The next step was measuring the microstructure, physico-chemical, phytochemical, antioxidant and in vitro release profiles.

\section{Material and methods}

The turmeric (Curcuma longa L.) used in this study originated in Yogyakarta, Indonesia. The maltodextrin, modified cassava flour, and skim milk were from Semarang, Indonesia. The turmeric was ground by means of a herb grinder (Getra Herb Grinder IC-10B) whose softness was an 80 to 100 mesh. In short, $100 \mathrm{~mL}$ of ethanol $95 \%$ was used as a solvent to extract $10 \mathrm{~g}$ of turmeric powder by using a rotary vacuum evaporator (Polyscience PS7019-000); the temperature of extraction was $65^{\circ} \mathrm{C}$ in $4 \mathrm{~h}$.

The turmeric extract was distributed in four parts, then it was mixed with the encapsulants (maltodextrin, modified cassava flour, or skim milk) in a $10 \%$ concentration of the total weight basis. It was distributed into four samples, turmeric extract as a control (T0), turmeric extract in an amorphous matrix of maltodextrin (T1), turmeric extract in an amorphous matrix of modified cassava flour (T2), turmeric extract in an amorphous matrix of skim milk (T3). The turmeric extract with the encapsulant addition was subsequently freeze-dried for 40 $\mathrm{h}$ by means of a freeze dryer (Labfreez FD-18-MTP) at room temperature with the vacuum pressure below $200 \mu \mathrm{mHg}$ and the temperature of the condenser and freezing plate at $-40^{\circ} \mathrm{C}$ to evaporate the water and protect the bioactive compounds. The treated samples were milled and yielded a microencapsulated turmeric powder. All the chemical reagents were purchased from well-known companies including Sigma Aldrich and Merck.

\section{Proximate analysis of turmeric (Curcuma longa $L$.)}

The proximate analysis (moisture, lipid, protein, carbohydrate, fiber and ash content) of the microencapsulated turmeric was conducted according to AOAC (2005).

\section{Scanning electron microscopy}

The morphology analysis of microencapsulated turmeric was performed by using an (SEM-EDX JEOL JSM-6510LA) analytical scanning electron microscope. The samples were coated with a thin layer of platinum $(10 \mathrm{kV}$ vacuum mode, $5 \mu \mathrm{m}$ scale bar).

\section{Yield}

The yield percentage of microencapsulated turmeric was calculated as the total weight of microcapsules collected for each batch divided by the total weight of raw materials (Fang and Bhandari, 2011): 
Production yield $(\%)=($ mass of microcapsules/mass of raw material $) \times 100$

\section{Encapsulation efficiency}

The percentage of encapsulation efficiency was measured based on the method described by El-Say (2016).

\section{Solubility}

The solubility of microcapsules was calculated based on the method described by Khasanah et al. (2015).

\section{The value of moisture}

The analysis of moisture was calculated based on the method described AOAC (2005). Ten grams of turmeric microcapsules were dried in an oven (Universal Drying Oven UN55 Memmert) at $105^{\circ} \mathrm{C}$ for $12 \mathrm{~h}$. Then, the samples were cooled in a desiccator for an extended period before measuring the final weight.

\section{The value of water activity}

The measurement of water activity $\left(\mathrm{a}_{\mathrm{w}}\right)$ level of turmeric microcapsules was by an (Aqualab 4TE) water activity meter. Turmeric microcapsule was loaded into the cup of $a_{w}$ meter. The reading was taken for \pm 4 min.

\section{Colour test}

The colour analysis of the treated sample was determined by a colorimeter ( $3 \mathrm{nh}$ colorimeter NH310). The white standard plate was used to calibrate the colorimeter. Treated samples were exposed to light for 30 minutes before readings. The level of lightness $\left(\mathrm{L}^{*}\right)$, redness $\left(\mathrm{a}^{*}\right)$ and yellowness $\left(\mathrm{b}^{*}\right)$ for statistical analysis were the averages of five random readings performed in each experimental unit.

\section{Total phenolic content (TPC)}

The TPC of the turmeric microcapsule was determined by the Folin-Ciocalteu reagent as shown by Çam and Hișil (2010) with slight modifications. One millilitre of diluted turmeric microcapsule solution $(0.8 \mathrm{mg} / \mathrm{mL})$ was dissolved with FolinCiocalteu reagent $5 \mathrm{~mL}$ of $(500 \mu \mathrm{L})$ concentration. Then, the dissolved solution was pre-diluted with distilled water. The mixture was kept at room temperature for 5 min, then $4 \mathrm{~mL} \mathrm{Na}_{2} \mathrm{CO}_{3}$ solution of $(7.5 \%)$ concentration was added. The mixture solution was vortexed by means of a (Vortex Mixer 120V Thermo Scientific) vortex mixer and the absorbance value was calculated by a (Genesys 10S UV-VIS Thermo Scientific) spectrophotometer at $765 \mathrm{~nm}$. The calculation of the total phenolic content (TPC) was estimated by a gallic acid standard curve. The results were expressed as mg gallic acid equivalent/g of freeze-dried extract (mg GAE/g).

\section{Total flavonoid content (TFC)}

The TFC of the turmeric microcapsule was estimated by the method from Wijekoon et al. (2011). The solution obtained from $500 \mu \mathrm{L}$ diluted sample $(0.8$ $\mathrm{mg} / \mathrm{mL}), 2.5 \mathrm{~mL}$ aquadest and $150 \mu \mathrm{L}$ of $\mathrm{NaNO}_{2}(5 \%)$ was mixed with $300 \mu \mathrm{L}$ $\mathrm{AlCl}_{3}(10 \%)$. The mixture was kept at room temperature for $5 \mathrm{~min}$, then $1 \mathrm{~mL}$ $\mathrm{NaOH}(1 \mathrm{M})$ and $550 \mu \mathrm{L}$ aquadest were added. The mixture solution was vortexed using a (Vortex Mixer 120V Thermo Scientific). The absorbance value was read by 
means of a (Genesys 10S UV-VIS Thermo Scientific) spectrophotometer at 510 $\mathrm{nm}$. The standard concentration used quercetin. The results were expressed as $\mathrm{mg}$ quercetin equivalent/g of freeze-dried extract (mg QE/g).

\section{Total tannin content (TTC)}

The TTC of the treated sample was determined by the Folin-Ciocalteu method as shown by Tambe and Bhambar (2014) with minor modifications. The volume of $0.1 \mathrm{~mL}$ sample extract $(1 \mathrm{mg})$ was mixed with $0.5 \mathrm{~mL}$ Folin-Ciocalteu reagent and $7.5 \mathrm{~mL}$ aquadest, followed by the addition of $1 \mathrm{~mL} \mathrm{Na} \mathrm{CO}_{3}(35 \%)$ and $0.9 \mathrm{~mL}$ aquadest for the above mixture. The mixture solution was vortexed by a (Vortex Mixer 120V Thermo Scientific) and incubated for $30 \mathrm{~min}$. The absorbance was measured by a spectrophotometer (Genesys 10S UV-VIS Thermo Scientific) at 725 $\mathrm{nm}$. The results were reported as $\mathrm{mg}$ tannic acid equivalent/g of freeze-dried extract (mg TE/g).

\section{Ascorbic acid content (AAC)}

The AAC of the treated sample was estimated by means of the method in Denre (2014) with minor modifications. The mixture of $1 \mathrm{~mL}$ sample extract (500 $\mathrm{mg} / \mathrm{mL}$ ) and $1 \mathrm{~mL}$ trichloroacetic acid solution (5\%) was followed by centrifugation with a centrifuge (5804R Centrifuge Eppendorf) at $3500 \mathrm{rpm}$ for 15 min. In brief, $0.1 \mathrm{~mL}$ of DTC (2.4 dinitrophenylhydrazine/thiourea/copper) solution was mixed with $0.5 \mathrm{~mL}$ of the supernatant and incubated at $37^{\circ} \mathrm{C}$ for $3 \mathrm{~h}$, then $0.75 \mathrm{~mL} \mathrm{H}_{2} \mathrm{SO}_{4}(65 \%)$ was added to the mixture. The mixture was kept at room temperature for $30 \mathrm{~min}$. The mixture absorbance was measured using a spectrophotometer (Genesys 10S UV-VIS Thermo Scientific) at $520 \mathrm{~nm}$. The results were expressed as $\mathrm{mg}$ ascorbate equivalent/100 $\mathrm{g}$ of freeze-dried extract (mg AE/100 g).

\section{The value of DPPH radical scavenging activity}

The DPPH value of the treated sample was determined by the method described by Brand-Williams et al. (1995). In short, $5 \mathrm{~g}$ of turmeric microcapsule was diluted with $15 \mathrm{~mL}$ aquadest. Then, $1 \mathrm{~mL}$ DPPH solution $(0.2 \mathrm{mM})$ was added in $200 \mu \mathrm{L}$ turmeric microcapsule solution, and the mixture was diluted in $800 \mu \mathrm{L}$ aquadest. The mixture was kept in the dark for $30 \mathrm{~min}$. The mixture absorbance was measured using a spectrophotometer (Genesys 10S UV-VIS Thermo Scientific) at $517 \mathrm{~nm}$. The results were expressed as follows:

$$
\text { DPPH }(\%)=1-(\text { absorbance of solution/absorbance of control }) x 100
$$

\section{Ferric reducing antioxidant power}

The value of the ferric reducing antioxidant power was estimated based on the method in Shon et al. (2003) with minor modifications. One millilitre of methanolic extract was mixed with $2.5 \mathrm{~mL} \mathrm{C}_{6} \mathrm{~N}_{6} \mathrm{FeK}_{3}(1 \%)$ and $2.5 \mathrm{~mL}$ phosphate buffer saline $(20 \mathrm{M})$. The mixture was incubated at $50^{\circ} \mathrm{C}$ for $30 \mathrm{~min}$. Then, $2.5 \mathrm{~mL}$ $\mathrm{C}_{2} \mathrm{HCl}_{3} \mathrm{O}_{2}(10 \%)$ was added to the mixture, and the result was centrifuged in a centrifuge (5804R Centrifuge Eppendorf) at $4000 \mathrm{rpm}$ for $15 \mathrm{~min}$. Five millilires of supernatant was mixed with $500 \mu \mathrm{L} \mathrm{FeCl}_{3}(1 \%)$ and $5 \mathrm{~mL}$ aquadest. The mixture 
was kept at room temperature for $15 \mathrm{~min}$. The mixture absorbance was measured using a spectrophotometer (Genesys 10S UV-VIS Thermo Scientific) at $700 \mathrm{~nm}$. The results were expressed as $\mathrm{mg}$ quercetin equivalent/g of freeze-dried extract (mg QE/g CE).

\section{In vitro release of microcapsules}

The in vitro release of curcumin was determined based on the method described by Das et al. (2010). The medium for the release of curcumin was phosphate-buffered saline (PBS), simulated intestinal fluid (SIF) and simulated gastric fluid (SGF). In short, $55 \mathrm{mg}$ of the treated sample was dissolved individually in $11 \mathrm{~mL}$ of PBS with $\mathrm{pH} 7.4$, SIF with $\mathrm{pH} 6.8$ and SGF with $\mathrm{pH} 1.2$, in order to obtain $5 \mathrm{mg} / \mathrm{mL}$. One millilitre of the mixture was placed in a sterile microcentrifuge tube (Eppendorf Safe-Lock $1.5 \mathrm{~mL}$ ), then the tubes were kept in a shaker (GS-20 AKMLab Orbital Shaker) at $150 \mathrm{rpm}$ in room temperature. The time-release intervals were $0,1,2,4,6,12,24,48,72,96$ and $192 \mathrm{~h}$, at a temperature of $37^{\circ} \mathrm{C}$. Briefly, after the time-release periods, the tube was centrifuged with a centrifuge (5804R Centrifuge Eppendorf) at $1500 \mathrm{rpm}$ for $15 \mathrm{~min}$. The treated sample was mixed with $4 \mathrm{~mL} \mathrm{C}_{2} \mathrm{H}_{5} \mathrm{OH}$, then the mixture absorbance was measured using a spectrophotometer (Genesys 10S UV-VIS Thermo Scientific) at $425 \mathrm{~nm}$. The results of curcumin release were expressed by the equation:

$$
\text { Curcumin release }(\%)=(\text { curcumin released/curcumin total }) \times 100
$$

\section{Statistical analysis}

Statistical analysis for all the data at different parameters was conducted by means of SPSS 16.0. One-way ANOVA was used to determine the significance level $(p<0.05)$ under a completely randomized design (CRD). Duncan's Mean Range Test (DMRT) was used to compare the means. Five replications were used for all parameters.

\section{Results and discussion}

\section{Proximate analysis of turmeric (Curcuma longa $L$.)}

The proximate analysis is a basic parameter used to determine turmeric (Curcuma longa L.) quality. The nutritional composition of turmeric consisted of moisture $(13.87 \pm 0.30)$, protein $(6.38 \pm 0.32)$, lipid $(2.83 \pm 0.36)$, fibre $(4.51 \pm 0.29)$, ash $(3.43 \pm 0.12)$, carbohydrate $(68.98 \pm 0.62)$. According to the results in Chainani$\mathrm{Wu}$ (2003), the protein and lipid values of turmeric were $6.3 \%$ and $5.1 \%$. These values of protein and lipid are equal to our results. The result from Khan et al. (2010) stated that the nutritional composition of turmeric was protein $7.5 \%$, lipid $2.7 \%$ and ash $6.95 \%$. The value of protein is higher when compared with our findings. The difference in value between our findings and the others researchers' results was probably due to the different varieties of turmeric. The composition of turmeric is shown in Table 1. 
Table 1. Turmeric (Curcuma longa L.) composition.

\begin{tabular}{lc}
\hline Constituents & Quantity (\%) \\
\hline Moisture & $13.87 \pm 0.30$ \\
Protein & $6.38 \pm 0.32$ \\
Fiber & $4.51 \pm 0.29$ \\
Lipid & $2.83 \pm 0.36$ \\
Ash & $3.43 \pm 0.12$ \\
Carbohydrate & $68.98 \pm 0.62$ \\
\hline
\end{tabular}

The values are expressed as the means \pm standard deviation

\section{Morphological analysis of microcapsules}

The microstructure analysis showed spherical, cubic, and some elongated structures as seen in Figure 1. This can be due to the high humidity of the microcapsules. Minemoto et al. (2002) stated that the vacuum pressure, the temperature of the condenser, and freezing plate could be some of the main effects of the freeze-drying process on the potential shape of the microcapsules.

A)
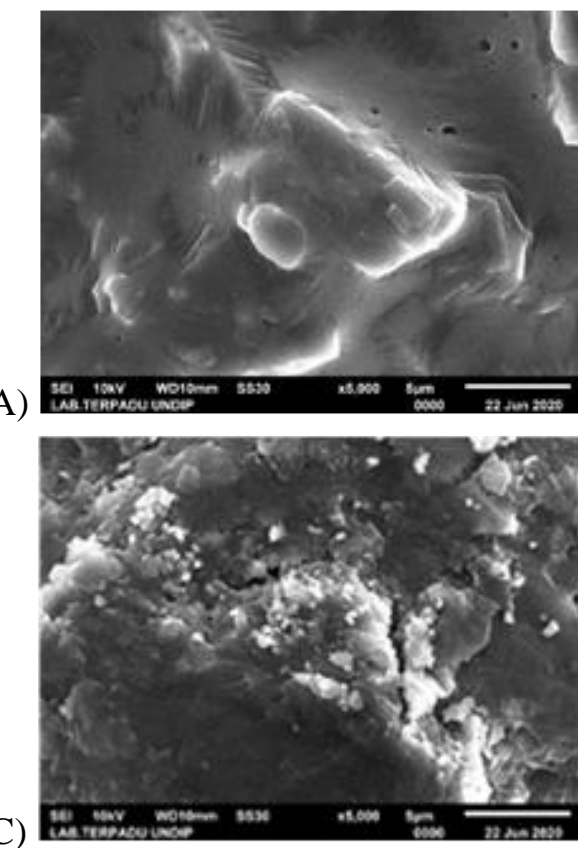

B)

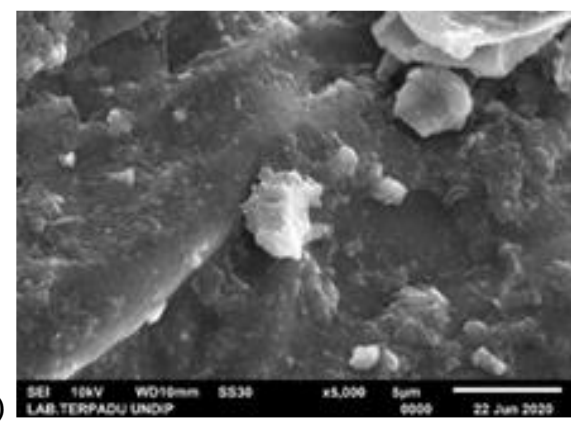

D)

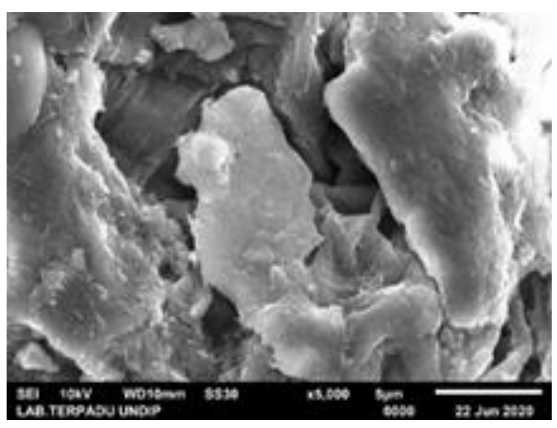

Figure 1. Scanning electron microscope (SEM) image (5000x) of turmeric microencapsulation. A) T0; B) T1; C) T2; D) T3.

The duration of the freeze-drying process causes a diffusion of the core, thus producing shrinkage in the microcapsules. Kurozawa et al. (2009) stated that the surface shape of the microcapsules can shrink due to the effect of encapsulants. Tonon et al. (2011) researched the different uses of the wall materials making up the compact structure of the turmeric microcapsule, which is marked by the incorporation formation between molecules and can be seen in a very large number 
of starch granules. The coating material also affects the shape of the surface morphology of the microcapsules. The small viscosity of the coating material will produce a thin wall, making it easier for the core material of the microcapsules to migrate (Minemoto et al., 2002).

\section{Physicochemical analysis}

\section{Moisture}

Moisture content is a parameter that determines the quality of microcapsules. Based on Table 2, the moisture content of turmeric microcapsules was significantly lower $(p<0.05)$ in T1, T2, and T3 when compared with T0. The lower level of moisture content may be due to the freeze-drying process. Cherrat et al. (2019) reported that the lower level of moisture content is influenced by the freeze-drying process which led to a high moisture evaporation rate. A low moisture content can prevent the growth of pathogenic bacteria. According to Yuliani et al. (2006), the quantity of moisture content for microcapsule products ranges from 2 to $6 \%$. The moisture content of microcapsules is influenced by the use of coating material. In this study, the coating materials were maltodextrin, modified cassava flour, and skim milk. The moisture content of the microencapsulated turmeric with the addition of maltodextrin showed the lowest value. This is presumably because the molecular weight of maltodextrin is lower than that of other coating materials. Fazaeli et al. (2012) stated that maltodextrin has a low molecular weight and a simple molecular structure so that water is easily evaporated during the drying period. The treated sample T3 showed a lower moisture content $(2.55 \pm 0.36)$ than the control. The lower value of the moisture content may be due to the simple molecular structure of skim milk as a microcapsule material. Pudziuvelyte et al. (2019) stated that skim milk powder as a microencapsulating material has a simple molecular structure and it is able to control the evaporation of moisture during the drying process.

\section{Water activity}

The measurement of the water activity $\left(\mathrm{a}_{\mathrm{w}}\right)$ of the treated samples showed significantly different results $(p<0.05)$. Based on Table 2 , the mean value of T1 showed the lowest water activity $(0.187 \pm 0.005)$, followed by T3 $(0.203 \pm 0.009)$, $\mathrm{T} 2(0.218 \pm 0.006)$ and $\mathrm{T} 0(0.225 \pm 0.010)$. The lower value of $\mathrm{a}_{\mathrm{w}}$ may be due to the fact that maltodextrin as an amorphous matrix reduced the total amount of moisture. Fazaeli et al. (2012) stated that the increase in the level of maltodextrin was followed by the increase in the evaporated moisture content. The microencapsulated turmeric in our findings contained water activity from 0.187 to 0.225 . Perera (2005) stated that the samples with the value of $a_{w}$ below 0.6 are safe from pathogenic bacteria in terms of the shelf-life stability of the products.

\section{Yield of microcapsule}

The yield value of the treated samples showed significantly different results $(p<0.05)$. The microencapsulated turmeric with the addition of maltodextrin (T1) indicated the highest yield $(86.79 \pm 0.37)$. The higher the yield, the higher the bioactive compound level contained in the turmeric microcapsule. The T1 treated 
sample shows the highest potential for the microencapsulated turmeric treatment to be used as a natural antioxidant as compared to the T0, T2, and T3 treatments. Some of the factors in the yield value include extraction effective solvents for dissolving endogenous compounds, plant varieties, conditions and size of sample powders, extraction conditions, and the process of solvent evaporation (Dudu et al., 2019).

\section{Encapsulation efficiency}

The percentages of encapsulation efficiency seen in microencapsulated turmeric were significantly different $(\mathrm{p}<0.05)$. The $\mathrm{T} 1$ treated sample had the highest result $(80.12 \pm 0.41)$, followed by T0 (79.34 \pm 0.24$), \mathrm{T} 3(78.45 \pm 0.18)$, and T2 (76.68 \pm 0.22 ). The value of encapsulation efficiency in the treated sample has a similar trend with the yield. Turmeric with the addition of maltodextrin (T1) significantly $(\mathrm{p}<0.05)$ improved the yield and encapsulation efficiency to the value of $86.79 \pm$ 0.37 and $80.12 \pm 0.41$, respectively. This may be due to the molecular structure of maltodextrin that could form a strong protective matrix around the core material and increases the viscosity level in the dispersed phase. Our findings were in line with El-Say (2016) who stated that the increase of yield is followed by higher encapsulation efficiency.

Table 2. Physicochemical analysis of freeze-drying microencapsulation of Curcuma longa L. in an amorphous matrix of maltodextrin, modified cassava flour and skim milk.

\begin{tabular}{ccccc}
\hline & & \multicolumn{2}{c}{ Treatment } & \\
& T0 & T1 & T2 & T3 \\
\hline Moisture (\%) & $2.96 \pm 0.13^{\mathrm{a}}$ & $2.33 \pm 0.24^{\mathrm{c}}$ & $2.81 \pm 0.15^{\mathrm{ab}}$ & $2.55 \pm 0.36^{\mathrm{bc}}$ \\
Water activity & $0.225 \pm 0.010^{\mathrm{a}}$ & $0.187 \pm 0.005^{\mathrm{c}}$ & $0.218 \pm 0.006^{\mathrm{a}}$ & $0.203 \pm 0.009^{\mathrm{b}}$ \\
Yield (\%) & $86.01 \pm 0.13^{\mathrm{b}}$ & $86.79 \pm 0.37^{\mathrm{a}}$ & $84.06 \pm 0.33^{\mathrm{c}}$ & $85,64 \pm 0.51^{\mathrm{b}}$ \\
Encapsulation & $79.34 \pm 0.24^{\mathrm{b}}$ & $80.12 \pm 0.41^{\mathrm{a}}$ & $76.68 \pm 0.22^{\mathrm{c}}$ & $78.45 \pm 0.18^{\mathrm{b}}$ \\
efficiency (\%) & & & & \\
Solubility (\%) & $94.92 \pm 0.23^{\mathrm{b}}$ & $98.78 \pm 0.23^{\mathrm{a}}$ & $94.88 \pm 0.27^{\mathrm{b}}$ & $95.28 \pm 0.61^{\mathrm{b}}$ \\
\hline
\end{tabular}

abc Means in the same raw are different at $p<0.05$

\section{Solubility of microcapsule}

Solubility is related to the release of bioactive compounds in terms of the microencapsulation process. Based on Table 2 , the water solubility values were significantly different $(p<0.05)$ between $\mathrm{T} 1$ and $\mathrm{T} 0, \mathrm{~T} 2, \mathrm{~T} 3$. The treated sample (T3) has a solubility of $98.78 \pm 0.23$, it was the highest value among the other treatments. The high solubility of microcapsules may be due to maltodextrin which can dissolve completely in cold water so that it can release flavour quickly in certain applications. The factors that affect water solubility in maltodextrin are the level of dextrose equivalency (DE). The higher level of DE value is followed by an increase in the level of solubility (Kenyon and Anderson, 1998).

\section{Hunter's color analysis}

The lightness $\left(\mathrm{L}^{*}\right)$ value of the T0, T1, T2, and T3 treated samples showed significantly different results $(p<0.05)$ as listed in Table 3 . The T1 treated sample 
had the highest $\mathrm{L}^{*}$ value, followed by T2, T3, and T0. Turmeric (Curcuma longa $L$.) with the addition of maltodextrin showed the highest brightness level because the number of polysaccharide molecules in turmeric increases with the addition of the maltodextrin as an amorphous matrix material. Sanchez et al. (2013) reported that the lightness of the substance can be increased by increasing the filler material because the number of polysaccharides in the molecules filler material is increased so that the color of the product becomes brighter.

The value of $a^{*}$ represents the degree of redness, and the value of $b^{*}$ represents the level of yellowness (Lucia et al., 2002). Based on Table 3, the a* value in the T1 treated sample showed a significantly higher result $(p<0.05)$ when compared with the T0, T2, T3 treated samples.The T1 treated sample showed the lowest a* value than the T0, T2 and T3 treated samples. This may be due to maltodextrin which, as a coating material in turmeric (Curcuma longa L.), affected the increased level of lightness, and also caused a decrease in the $\mathrm{a}^{*}$ value when compared to the control. The higher value of lightness affects the lower value of redness in the treated samples.

Table 3. Hunter's colour analysis of freeze-drying microencapsulation of Curcuma longa $L$. in an amorphous matrix of maltodextrin, modified cassava flour and skim milk

\begin{tabular}{cccc}
\hline Treatment & $\begin{array}{c}\text { Lightness } \\
\left(\mathbf{L}^{*}\right)\end{array}$ & $\begin{array}{c}\text { Redness } \\
\left(\mathbf{a}^{*}\right)\end{array}$ & $\begin{array}{c}\text { Yellowness } \\
\left(\mathbf{b}^{*}\right)\end{array}$ \\
\hline T0 & $47.75 \pm 0.34^{\mathrm{d}}$ & $17.32 \pm 0.44^{\mathrm{a}}$ & $23.95 \pm 0.20^{\mathrm{d}}$ \\
T1 & $53.72 \pm 0.38^{\mathrm{a}}$ & $16.70 \pm 0.30^{\mathrm{b}}$ & $32.06 \pm 0.33^{\mathrm{a}}$ \\
T2 & $51.47 \pm 0.49^{\mathrm{b}}$ & $17.39 \pm 0.38^{\mathrm{a}}$ & $27.76 \pm 0.29^{\mathrm{b}}$ \\
T3 & $48.57 \pm 0.48^{\mathrm{c}}$ & $17.19 \pm 0.20^{\mathrm{a}}$ & $25.18 \pm 0.36^{\mathrm{c}}$ \\
\hline
\end{tabular}

${ }^{a b c}$ Means in the same column are different at $p<0.05$

The yellowness level $\left(b^{*}\right)$ of the $\mathrm{T} 1$ treated sample was significantly different $(p<0.05)$ as compared to T2, T3 and control (T0). The turmeric (Curcuma longa L.) with the addition of maltodextrin (T1) showed the highest $b^{*}$ value among the other treatments. This may be due to maltodextrin which causes an increased level of yellow color in turmeric, so the T1 treatment has the highest yellowness level. The combination of high $\mathrm{a}^{*}$ value and low $\mathrm{b}^{*}$ value will decrease the lightness of the product. Meanwhile, the lower $a^{*}$ value and the higher of $b^{*}$ value indicates the increased level of lightness (Hutching, 1999).

\section{Phytochemical and antioxidant analysis}

Total phenolic content (TPC)

The quantity of total phenol in the microencapsulated turmeric was significantly different $(\mathrm{p}<0.05)$. The mean value of $\mathrm{T} 1$ showed the highest total phenolic content $(86.89 \pm 0.42)$, followed by T3 $(85.56 \pm 0.42), \mathrm{T} 2(83.31 \pm 0.54)$, and T0 $(81.69 \pm$ 0.35 ). The highest TPC was found in the T1 treated sample, which can be due to the fact that maltodextrin as a coating material has a strong effect on protecting the phenolic compounds in turmeric. Shen and Ji (2012) stated that curcuminoids are the major phenolic compounds in turmeric and they may be considered as natural 
antioxidants. Sanchez et al. (2013) reported that the increased level of phenolic compounds is the consequence of moisture evaporation and the addition of maltodextrin.

\section{Total flavonoid content (TFC)}

The results of total flavonoids in the treated samples were significantly different $(\mathrm{p}<0.05)$. The mean value of the $\mathrm{T} 1$ showed the highest total flavonoid content $(130.29 \pm 1.22)$, followed by T3 (127.32 \pm 0.76$)$, T2 (119.22 \pm 0.70$)$, and T0 $(117.62 \pm 1.54)$. The value of total flavonoid content in the treated sample has a similar trend with the total phenolic content. The reaction between curcuminoids and aluminum chloride is equal with the reaction between flavonoids and aluminum chloride, although flavonoids are not classified as curcuminoids (Sepahpour et al., 2018). The keto form configuration in curcuminoids acts like the major component and it is equal with the reaction between flavonoids and $\mathrm{AlCl}_{3}$ (Priyadarsini, 2014). Therefore, the high amount of curcuminoids in the treated sample could be equal to the higher value of flavonoid content.

Table 4. Phytochemical analysis of freeze-drying microencapsulation of Curcuma longa $L$. in an amorphous matrix of maltodextrin, modified cassava flour and skim milk.

\begin{tabular}{ccccc}
\hline Treatment & $\begin{array}{c}\text { Total phenolic } \\
(\mathbf{m g ~ G A E} / \mathbf{g})\end{array}$ & $\begin{array}{c}\text { Total flavonoid } \\
(\mathbf{m g ~ Q E} / \mathbf{g})\end{array}$ & $\begin{array}{c}\text { Total tannin } \\
(\mathbf{m g} \text { TE/g) }\end{array}$ & $\begin{array}{c}\text { Ascorbic acid } \\
(\mathbf{m g ~ A E} / \mathbf{1 0 0} \text { g) }\end{array}$ \\
\hline T0 & $81.69 \pm 0.35^{\mathrm{d}}$ & $117.62 \pm 1.54^{\mathrm{d}}$ & $93.60 \pm 1.10^{\mathrm{d}}$ & $0.04 \pm 0.004^{\mathrm{c}}$ \\
T1 & $86.89 \pm 0.42^{\mathrm{a}}$ & $130.29 \pm 1.22^{\mathrm{a}}$ & $98.18 \pm 0.82^{\mathrm{a}}$ & $0.06 \pm 0.009^{\mathrm{a}}$ \\
T2 & $83.31 \pm 0.54^{\mathrm{c}}$ & $119.22 \pm 0.70^{\mathrm{c}}$ & $94.62 \pm 0.67^{\mathrm{c}}$ & $0.04 \pm 0.005^{\mathrm{c}}$ \\
T3 & $85.56 \pm 0.42^{\mathrm{b}}$ & $127.32 \pm 0.76^{\mathrm{b}}$ & $95.56 \pm 0.62^{\mathrm{b}}$ & $0.05 \pm 0.006^{\mathrm{b}}$ \\
\hline
\end{tabular}

${ }^{a b c}$ Means in the same column are different at $p<0.05$

\section{Total tannin content (TTC)}

The quantity of total tannin in the treated samples showed a significant result $(\mathrm{p}<0.05)$. The mean value of $\mathrm{T} 1$ indicated the highest total tannin content $(98.18 \pm$ $0.82)$, followed by T3 $(95.56 \pm 0.62)$, T2 $(94.62 \pm 0.67)$, and T0 $(93.60 \pm 1.10)$. The result showed a higher value of T1 when compared with the T0, T2 and T3 treated samples. This indicated that turmeric microcapsules with an amorphous matrix of maltodextrin were a higher source of tannins than other treatments. Tanvir et al. (2015) stated that tannins are a class of polyphenolic molecules that have been reported to have antioxidant activities.

Ascorbic acid content (AAC)

The AAC value of microencapsulated turmeric showed significant results $(\mathrm{p}<0.05)$, as listed in Table 4 . The mean value of $\mathrm{T} 1$ showed the highest total AAC content $(0.06 \pm 0.009)$, followed by T3 $(0.05 \pm 0.006), \mathrm{T} 2(0.04 \pm 0.005)$, and T0 $(0.04 \pm$ $0.004)$. The mean value of $\mathrm{T} 2$ and $\mathrm{T} 0$ showed no significant difference. The ascorbic acid of the treated sample has a similar trend with TPC, TFC and TTC. This indicates the amorphous matrix made of maltodextrin, modified cassava flour, and skim milk protected the bioactive compound of the turmeric extract. Ascorbic acid is one of the strong antioxidant compounds that interact with reactive oxygen 
species, and ascorbic acid terminates the free radicals by electron transfer (Tambe and Bhambar, 2014).

\section{DPPH radical scavenging activity}

The results of the DPPH radical scavenging activity seen in Table 5 were significantly different $(p<0.05)$. The T1 treated sample had the highest DPPH value (67.86 \pm 0.47$)$, followed by T3 (65.86 \pm 0.52$)$, T2 (64.67 \pm 1.14$)$, and T0 (64.03 \pm $0.19)$. The $\mathrm{T} 1$ treated sample showed the highest antioxidant capacity. This result was in line with the highest microcapsule yield of the T1 treated sample among the other treatments. The higher yield result indicates the increased level of antioxidant compounds contained in the sample. The mechanism of antioxidants usually occurs when the initiation or propagation reactions occur in the substrate by absorbing free radicals and decomposing the peroxide (Nimse and Pal, 2015). Turmeric has a high value of free radical inhibitory activity when tested using different variations of the solvent (Nisar et al., 2015).

Table 5. Antioxidant analysis of freeze-drying microencapsulation of Curcuma longa L. in an amorphous matrix of maltodextrin, modified cassava flour and skim milk.

\begin{tabular}{ccc}
\hline Treatment & $\begin{array}{c}\text { DPPH radical scavenging activity } \\
(\boldsymbol{\%})\end{array}$ & $\begin{array}{c}\text { Ferric reducing antioxidant } \\
\text { power }(\mathbf{m g} \mathbf{Q E} / \mathbf{g})\end{array}$ \\
\hline T0 & $64.03 \pm 0.19^{\mathrm{c}}$ & $25.07 \pm 0.93^{\mathrm{c}}$ \\
T1 & $67.86 \pm 0.47^{\mathrm{a}}$ & $32.38 \pm 0.53^{\mathrm{a}}$ \\
T2 & $64.67 \pm 1.14^{\mathrm{c}}$ & $25.59 \pm 0.60^{\mathrm{c}}$ \\
T3 & $65,86 \pm 0.52^{\mathrm{b}}$ & $29.53 \pm 0.52^{\mathrm{b}}$ \\
\hline
\end{tabular}

abc Means in the same column are different at $\mathrm{p}<0.05$

\section{Ferric reducing antioxidant power (FRAP)}

The FRAP content in the treated samples showed a significant result $(\mathrm{p}<0.05)$, as listed in Table 5. The mean value of T1 showed the highest total FRAP content $(32.38 \pm 0.53)$, followed by T3 $(29.53 \pm 0.52), \mathrm{T} 2(25.59 \pm 0.60)$, and T0 (25.07 \pm $0.93)$. The value of the FRAP content in the treated sample has a similar trend with the DPPH radical scavenging activity. This indicates turmeric with the addition of an amorphous matrix had higher antioxidant properties than the control. Borra et al. (2003) stated that the antioxidant compounds in the turmeric sample reduce $\mathrm{Fe}^{3+}$ in potassium ferricyanide to $\mathrm{Fe}^{2+}$, thus breaking the radical chain reaction. The higher value of phenolic and flavonoid content triggers a higher level of ferric reducing antioxidant power.

\section{In vitro release of microencapsulated turmeric}

The direct dispersion methods in three different $\mathrm{pH}$ conditions were implemented in the release profile of microencapsulated turmeric.

\section{Release profile at phosphate-buffered saline}

The turmeric microcapsules' release profile in PBS (pH 7.4) is shown in Figure 2. The initial release of curcumin in microencapsulated turmeric was reported to be controlled in the first $1 \mathrm{~h}$ to 8 days. The release process of curcumin from each 
amorphous matrix in an initial interval of $6 \mathrm{~h}$ was the most important period for release because nearly $50 \%$ of the curcumin release was reported within that timeframe. The percentage of curcumin release did not significantly change after 6 $\mathrm{h}$. The release profile of microencapsulated turmeric was influenced by maltodextrin, modified cassava flour, and skim milk as coating materials. This coating material extended the curcumin release in phosphate-buffered saline with $\mathrm{pH}$ 7.4. In the period of 8 days, the T1 treated sample showed the lowest total release $(48.44 \%)$, followed by T3 $(48.68 \%)$, T2 (49.04\%), and T0 (49.47\%). Sahu et al. (2008) stated that the value of the curcumin release profile is influenced by the amount of entrapped curcumin near the surface of microcapsules.

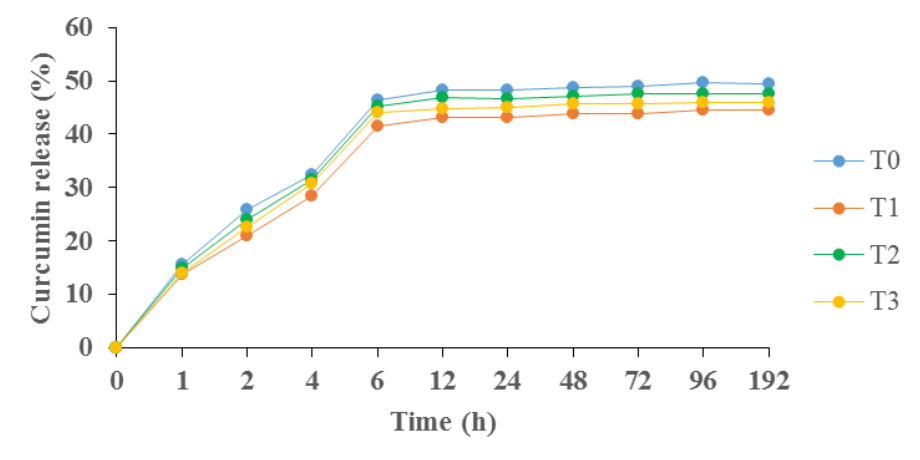

Figure 2. Microencapsulation of turmeric at PBS.

Release profile at simulated gastric fluid

The turmeric microcapsules release profile in SGF (pH 1.2) is shown in Figure 3.

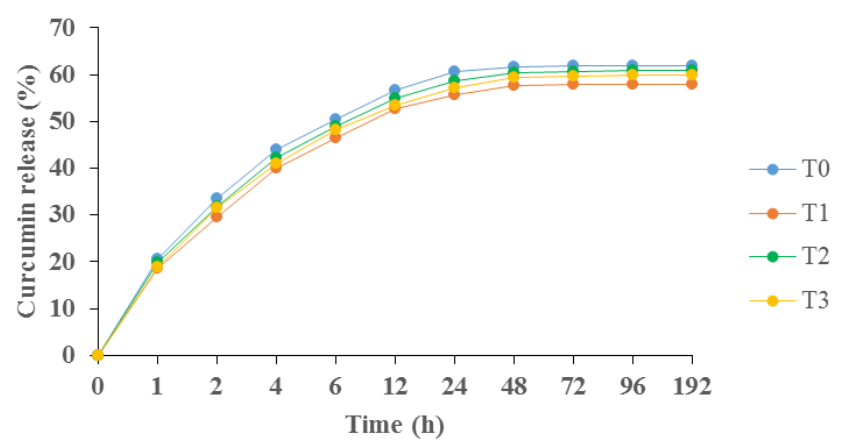

Figure 3. Microencapsulation of turmeric at SGF.

It was reported that the curcumin release profile of $\mathrm{T} 1$ showed the lowest value $(60.76 \%)$, followed by T3 $(60.80 \%)$, T2 $(60.91 \%)$, and T0 $(61.02 \%)$. The turmeric with the addition of maltodextrin, modified cassava flour, and skim milk as coating materials showed a lower value of curcumin release than the control. The release process of curcumin from each coating material showed that the initial $24 \mathrm{~h}$ was the most important period for release because more than $60 \%$ of the curcumin release 
was reported within this timeframe. The percentage of curcumin release did not significantly change after $24 \mathrm{~h}$. The percentage of curcumin release in SGF that was higher than PBS may be due to the acidic pH condition, as the hydrolysis of curcumin was faster in an acidic medium. Our findings were equal to Nishi et al. (2007) who stated that simulated gastric fluid was faster than the simulated intestinal fluid in terms of ampicillin-conjugated gum arabic releasing profile.

\section{Release profile at simulated intestinal fluid}

The release profile of turmeric microcapsules for the simulated intestinal fluid (SIF) with pH 6.8 is shown in Figure 4. In the first $1 \mathrm{~h}$, the value of T1 (16.45\%), T3 $(16.78 \%)$, T2 (17.23\%), and T0 (17.84\%) of curcumin release was identified. Then, the in vitro release profile of microencapsulated turmeric was increased in T1 $(55.83 \%)$, followed by T3 $(55.93 \%)$, T2 $(55.95 \%)$, and T0 $(56.03 \%)$ over a period of 8 days. The rapid release in the simulated intestinal fluid (SIF) was due to the curcumin that was adsorbed or weakly bound to the surface area of the microcapsules, and the precipitation of wall materials at $\mathrm{pH}$ 6.8. Moreover, the release was lower when the coating materials were applied. The study by Sahu et al. (2008) reported that the in vitro release profile of micelle nanoparticles in curcumin in a stimulated intestinal fluid medium yielded $84 \%$ of curcumin release in $48 \mathrm{~h}$. The turmeric microcapsules' release profile in the simulated intestinal fluid was lower than SGF due to the lower solubility of curcumin in base $\mathrm{pH}$ solutions. Based on the release profile result in various $\mathrm{pH}$ values, it was reported that the turmeric with the addition of encapsulants such as maltodextrin, modified cassava flour, and skim milk increased the curcumin release.

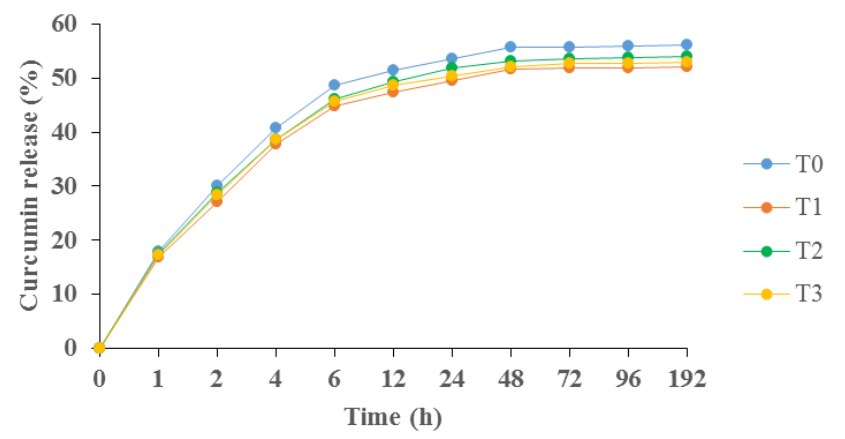

Figure 4. Microencapsulation of turmeric at SIF.

\section{Conclusions}

It can be concluded that an optimal treatment process is the freeze-drying microencapsulation of turmeric in an amorphous matrix of maltodextrin (T1), since it enabled high bioactive compounds with low values of moisture, water activity $\left(\mathrm{a}_{\mathrm{w}}\right)$, and curcumin release. Maltodextrin as a coating material in turmeric affected the increased level of yield, encapsulation efficiency, and solubility of the microcapsule. For instance, it showed a positive effect on the value of the total phenolic content, total flavonoid content, total tannin content, ascorbic acid 
content, and consequently had a higher antioxidant activity. Turmeric (Curcuma longa $L$.) with the addition of maltodextrin can be used as a natural antioxidant compound and natural colorant for food products.

\section{References}

AOAC. 2005. Official methods of analysis of AOAC International. $18^{\text {th }}$ ed. AOAC Int. Gaithersburg, MD, USA.

Brand-Williams, W., Cuvelier, M.E., Berset, C. 1995. Use of a free radical method to evaluate antioxidant activity. LWT-Food Science Technology, 28, 25-30.

Borra, S.K., Gurumurthy, P., Mahendra, J. 2013. Antioxidant and free radical scavenging activity of curcumin determined by using different in vitro and ex vivo models. Journal of Medicinal Plants Research, 7, 2680-2690.

Calvo, P., Castano, A.L., Hernandez, M.T., Gonzalez-Gomez, D. 2011 Effects of microcapsule constitution on the quality of microencapsulated walnut oil. European Journal of Lipid Science and Technology, 113, 1273-1280.

Çam, M., Hışıl, Y. 2010. Pressurised water extraction of polyphenols from pomegranate peels. Food Chemistry, 123, 878-885.

Chainani-Wu, N. 2003. Safety and antiinflammatory activity of curcumin: a component ofturmeric (Curcuma longa). The Journal of Alternative and Complementary Medicine, $\mathbf{9}$, 161-168.

Cherrat, S., Boulkebache-Makhlouf, L., Iqbal, J., Zeghichi, S., Sait, S. 2019. Effect of different drying temperatures on the composition and antioxidant activity of ginger powder. The Annals of the University of Dunarea de Jos of Galati. Fascicle VI. Food Technology, 43, 125-142.

Das, R.K., Kasoju, N., Bora, U. 2010. Encapsulation of curcumin in alginate-chitosan-pluronic composite nanoparticles for delivery to cancer cells. Nanomedicine, 6, 153-160.

Denre, M. 2014. The determination of vitamin C, total phenol and antioxidant activity of some commonly cooking spices crops used in West Bengal. International Journal of Plant Physiology and Biochemistry, 6, 66-70.

Dudu, O.E., Lin, L., Oyedeji, A.B., Oyeyinka, S.A., Ying, M. 2019. Structural and functional characteristics of optimised dryheat moisture treated cassava flour and starch. International Journal of Biological Macromolecules, 133, 1219-1227.

El-Say, K. 2016. Maximizing the encapsulation efficiency and the bioavailability of controlledrelease cetirizine microspheres using draper-lin small composite design. Drug Design Development and Therapy, 10, 825-839.

Fang, Z., Bhandari, B. 2011. Effect of spray drying and storage on the stability of bayberry polyphenols. Food Chemistry, 129, 1139-1147.

Fazaeli, M., Emam-Djomeh, Z., Kalbasi Ashtari, A., Omid, M. 2012. Effect of spray drying conditions and feed composition on the physical properties of black mulberry juice powder. Food and Bioproducts Processing, 90, 667-675.

Fu, N., Chen, X.D. 2011. Towards a maximal cell survival in convective thermal drying processes. Food Research International, 44, 1127-1149.

Galmarini, M.V., Schebor, C., Zamora, M.C., Chirife, J. 2009. The effect of trehalose, sucrose and maltodextrin addition on physicochemical and sensory aspects of freeze-dried strawberry puree. International Journal of Food Science and Technology, 44, 1869-1876. 
Gupta, S.C., Sung, B., Kim, J.H., Prasad, S., Li, S., Aggarwal, B.B. 2013. Multitargeting by turmeric, the golden spice: From kitchen to clinic. Molecular Nutrition and Food Research, 57, 1510-1528.

Hutching, J.B. 1999. Food Color and Appearance. Aspen Publisher Inc. Maryland.

Jeyakumari, A., Zynudheen, A.A., Parvathy, U. 2016. Microencapsulation of bioactive food ingredients and controlled release - A Review. MOJ Food processing and Technology, 2, 00059.

Kenyon, M.M., Anderson, R.J. 1998. Maltodextrin and Low-Dextrose-Equivalence Corn Syrup Solids. In: Flavour Encapsulation. Risch S.J., Reineccius, G.A, American Chemicla Society.

Khan, S., Makhija, I., Khamar, D., Rani, S. 2010. Development and standardization of turmeric cream by HPTLC. The International Journal of Psychiatry in Medicine, 109, 1-4.

Khasanah, L.U., Anandhito, B.K., Rachmawaty, T., Utami, R., Manuhara, G.J. 2015. Physical and chemical characteristics of cinnamon leaf (Cinnamomum burmannii) oleoresin microcapsule encapsulated with maltodextrin, arabic gum, and skim milk as coating material. Agritech, 35, 414-421.

Kocaadam, B.B., Sanlier, N. 2015. Curcumin, an active component of turmeric (Curcuma longa), and its effects on health. Critical Reviews in Food Science and Nutrition, 57, 28892895.

Kurozawa, L.E., Park, K.J., Hubinger, M.D. 2009. Effect of maltodextrin and gum arabic on water sorption and glass transition temperature of spray dried chicken meat hydrolysate protein. Journal of Food Engineering, 91, 287-296.

Lucia, M.A., Bambirra, M.L.A., Junqueira, R.G., Gloria, M.B.A. 2002. Influence of post harvest processing conditions on yield and quality of ground turmeric. Brazilian Archives of Biology and Technology, 45, 421-429.

Miean, K.H., Mohamed, S. 2001. Flavonoid (myricetin, quercetin, kaempferol, luteolin, and apigenin) content of edible tropical plants. Journal of Agricultural and Food Chemistry, 49, 3106-3112.

Minemoto, Y., Hakamata, K., Adachi, S., Matsuno, R. 2002. Oxidation of linoleic acid encapsulated with gum arabic or maltodextrin by spray-drying. Journal of Microencapsulation, 19, 181-189.

Miyamoto-Shinohara, Y., Imaizumi, T., Sukenobe, J., Murakami, Y., Kawamura, S., Komatsu, Y. 2000. Survival rate of microbes after freeze-drying and long-term storage. Cryobiology, 41, 251-255.

Nedovic, V., Kalusevic, A., Manojlovic, V., Levic, S., Bugarski, B. 2011. An overview of encapsulation technologies for food applications. Procedia Food Science, 1, 1806-1815.

Nimse, S.B., Pal, D. 2015. Free radicals, natural antioxidants, and their reaction mechanisms. Royal Society of Chemistry Advances, 5, 27986-28006.

Nisar, N., Li, L., Lu, S., Khin, N., Pogson, B. 2015. Carotenoid metabolism in plants. Molecular plant, 8, 68-82.

Nishi, K.K., Antony, M., Jayakrishnan, A. 2007. Synthesis and evaluation of ampicillinconjugated gum arabic microspheres for sustained release. Journal of Pharmacy and Pharmacology, 59, 485-493. 
Palamutoglu, R., Sarıçoban, C. 2019. Physico-chemical investigation and antioxidant activity of encapsulated fish collagen hydrolyzates with maltodextrin. The Annals of the University of Dunarea de Jos of Galati. Fascicle VI. Food Technology, 43, 94-105.

Perera, C. 2005. Selected quality attributes of dried foods. Drying Technology, 23, 717-730.

Priyadarsini, K. 2014. The chemistry of curcumin: From extraction to therapeutic agent. Molecules, 19, 20091-20112.

Pudziuvelyte, L., Marksa, M., Jakstas, V., Ivanauskas, L., Kopustinskiene, D.M., Bernatoniene, J. 2019. Microencapsulation of elsholtzia ciliata herb ethanolic extract by spray-drying: Impact of resistant-maltodextrin complemented with sodium caseinate, skim milk, and betacyclodextrin on the quality of spray-dried powders. Molecules, 24, 1461.

Putri, N., Herlina, H., Subagio, A. 2018. Characterization of the mocaf (modified cassava flour) based on milling method and fermentation time. Jurnal Agroteknologi, 12, 79-89.

Sanchez, V., Baeza, R., Galmarini, M.V., Zamora, M., Chirife, J. 2013. Freeze-drying encapsulation of red wine polyphenols in an amorphous matrix of maltodextrin. Food and Bioprocess Technology, 6, 1350-1354.

Sahu, A., Bora, U., Kasoju, N., Goswami, P. 2008. Synthesis of novel biodegradable and selfassembling methoxy poly(ethylene glycol)-palmitatenanocarrier for curcumin delivery to cancer cells. Acta Biomaterialia, 4, 1752-1761.

Sepahpour, S., Selamat. J., Manap, M.Y.A., Khatib, A., Razis, A.F.A. 2018. Comparative analysis of chemical composition, antioxidant activity and quantitative characterization of some phenolic compounds in selected herbs and spices in different solvent extraction systems. Molecules, 23, 402.

Shen, L., Ji, H.F. 2012. The pharmacology of curcumin: Is it the degradation products?. Trends in Molecular Medicine, 18, 138-144.

Shon, M.Y., Kim, T.H., Sung, N.J. 2003. Antioxidants and free radical scavenging activity of Phellinus baumii (Phellinus of Hymenochaetaceae) extracts. Food Chemistry. 82, 593-597.

Tambe, V.D., Bhambar, S. 2014. Estimation of total phenol, tannin, alkaloid and flavonoid in (Hibiscus tiliaceus Linn.) wood extracts. Journal of Pharmacognosy and Phytochemistry, 2, 41-47.

Tanvir, E.M., Afroz, R., Karim, N., Mottalib, M., Hossain, M., Islam, M.A., Gan, S., Khalil, D. 2015. Antioxidant and antibacterial activities of methanolic extract of BAU Kul (Ziziphus mauritiana), an improved variety of fruit from Bangladesh. Journal of Food Biochemistry, 39, 139-147.

Tonon, R.V., Grosso, C.R.F., Hubinger, M.D. 2011. Influence of emulsion composition and inlet air temperature on the microencapsulation of flaxseed oil by spray drying. Food Research International, 44, 282-289.

Vesterlund, S., Salminen, K., Salminen, S. 2012. Water activity in dry foods containing live probiotic bacteria should be carefully considered: A case study with Lactobacillus rhamnosus GG in flaxseed. International Journal of Food Microbiology, 157, 319-321.

Wijekoon, M.J.O., Bhat, R., Karim, A.A. 2011. Effect of extraction solvents on the phenolic compounds and antioxidant activities of bunga kantan (Etlingera elatior Jack.) inflorescence. Journal of Food Composition and Analysis, 24, 615-619.

Yuliani, S., Torley, P., D'Arcy, B., Nicholson, T., Bhandari, B. 2006. Extrusion of mixtures of starch and D-limonene encapsulated with $\beta$-cyclodextrin: Flavour retention and physical properties. Food Research International, 39, 318-331. 